\title{
Voltage Enhancement in Distribution System using Voltage Improvement Factor
}

\author{
A.K Sharma ${ }^{1}$, Tanuj Manglani ${ }^{2}$ \\ ${ }^{1,2}$ Assistant Professor, Department of Electrical Engineering, YIT, Jaipur, India
}

\begin{abstract}
A good distribution system should ensure that the voltage variations at consumer's terminals are within permissible limits. To improve the voltage profile in distribution systems, a new concept of Voltage Improvement Factor has been used in this paper. The proposed method is implemented on IEEE 15 bus radial distribution system.
\end{abstract}

Index Terms: Capacitor placement, capacitor sizing, distribution system, voltage profile, voltage improvement, Voltage improvement factor, VIF

\section{Introduction}

Distribution system is the final link between the high voltage transmission system and the consumer. The power flows through the distributor to feed the consumer load. The transfer of reactive power (VAr) over the line [1] causes voltage drop and hence the developed losses make the system inefficient. The permissible voltage variations is plus minus $5 \%$ of rated voltage at the consumer's terminals [2]. Thus, the compensation of reactive power is necessary for the enhancement of the voltage to make the system more reliable and efficient.

In the past, various methods have been proposed for reactive power compensation to improve the voltage profile such as analytical methods [3], numerical programming methods [4], heuristics methods [5], genetic algorithm [6], simulated annealing [7],fuzzy logic [8], PSO [9] and PGSA method [10]. In this paper, voltage profile improvement will be done by Var compensation using capacitor placement with the help of Voltage Improvement Factor (VIF). The proposed method is tested on 15 bus radial distribution systems.

\section{Problem Formulation}

The main problem is to minimize the losses which results in enhancement of voltage under certain operating constraints. There may be a number of solutions which may result in voltage improvement at system buses after capacitor placement but the optimal solution is obtained when the losses of the system is minimum. In the work, voltage profile will be improved by using optimum size of capacitors at buses. The problem formulation consists of two parts: Objective Function and Constraints.

\section{Minimize}

Objective function:

$\mathrm{F}=$ Minimize (Losses)

\section{Subject to constraints}

Voltage limit: $0.95 \leq \mathrm{V}_{\mathrm{i}} \leq 1.01$

Capacitor size limit: $Q_{i}^{c} \leq \sum_{i=1}^{n} Q_{L i}$

Here, $\mathrm{n}$ is the number of buses, $\mathrm{V}_{\mathrm{i}}$ is the voltage magnitude of bus i. $Q_{i}^{c}$ is the reactive power compensated at bus i and and $Q_{L i}$ is the reactive load power at bus i .

\section{Methodology}

Vector Based Distributed Load Flow [11] is used to calculate total losses and voltages at all buses. Using sensitivity analysis, Loss Sensitivity Factors [12] shall be used for the locations of capacitors in distribution system. Now, the voltage can be enhanced by placing the optimal sized capacitors at optimum locations of the buses. This can be done by using Voltage improvement factor (VIF).

Mathematically,

\section{Algorithm For VIF}

$$
\mathrm{VIF}=\frac{\mathrm{V}_{\text {New }}}{\mathrm{V}_{\text {Old }}}
$$

i) Input the system data such as line and load details of the distribution system, constraints limits etc.

ii) Indicate the minimum and maximum size of available capacitors. 
iii) Identify the candidate buses for capacitor placement using Loss Sensitivity Factors. The estimation of these candidate locations basically helps in reduction of the search space for the optimization procedure.

iv) Using VDLF, calculate losses and voltages at all buses. Say, the calculated losses be Fbest.

v) Place initial value of capacitor on buses.

vi) Again using VDLF, calculate VIF.

vii) If the above step (vi) results in losses less than initial value Fbest then save this solution as Fbest.

viii) Now increase the size of capacitor and place it on selected buses.

ix) Repeat (vi), (vii) and (viii) step till all the capacitors have been placed.

$\mathrm{x}$ ) From the above, minimum Fbest will be the optimal solution for voltage enhancement and will give optimal size of capacitors.

\section{Application of Proposed Method}

The proposed method has been programmed using MATLAB. The effectiveness of the proposed method for loss reduction by capacitor placement is tested on 15-bus test radial distribution systems [13]. The single line diagram is shown in Fig. 1. The rated line voltage of the system is $11 \mathrm{kV}$.

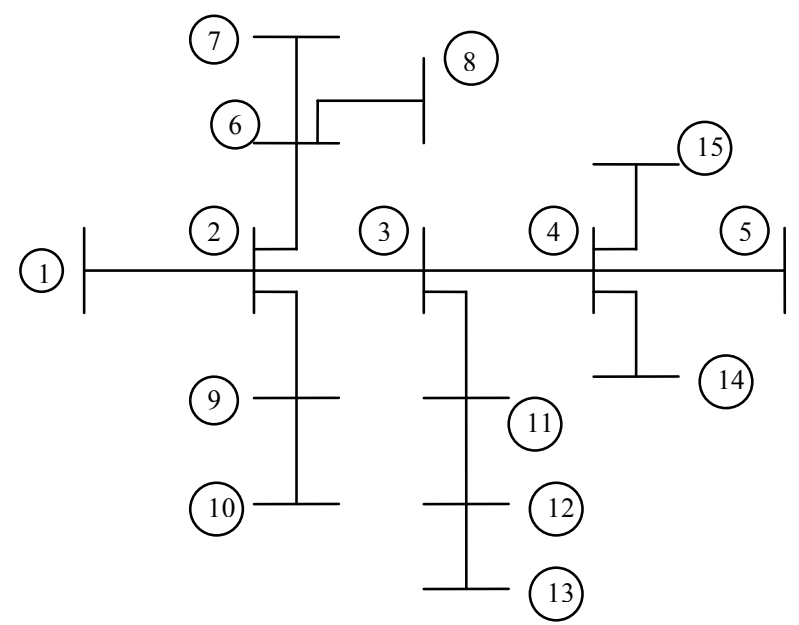

Fig.1 15-Bus Distribution Network

The voltage of the substation (bus number 1) is assumed to be 1 p.u. The method of sensitive analysis is used to select the candidate installation locations of the capacitors. The buses are arranged in the decreasing order of their loss sensitivity factor $\left(\partial P_{\text {lineloss }} / \partial Q_{\text {eff }}\right)$ (i.e bus $6,3,11,4,12,15,14,7,13,8$ and 5 ). Now, the capacitors are placed on these selected buses using proposed VIF with all possible combinations of buses. Table I shows the optimal locations of the buses and the corresponding size of capacitors obtained by using proposed method.

Table I Simulation Results of 15- Bus

\begin{tabular}{|c|c|c|c|}
\hline Parameters & Un-compensated & \multicolumn{2}{|c|}{$\begin{array}{c}\text { Compensated using } \\
\text { VIF }\end{array}$} \\
\hline $\begin{array}{c}\text { Voltage at bus } \\
\text { number 13 } \\
\text { (p.u.) }\end{array}$ & 0.9445 & \multicolumn{2}{|c|}{0.9694} \\
\hline $\begin{array}{c}\text { Total losses } \\
\text { (kW) }\end{array}$ & & \multicolumn{3}{|c|}{} \\
\hline Loss reduction & 61.8 & \multicolumn{2}{|c|}{30.46} \\
(\%) & --- & \multicolumn{2}{|c|}{50.71} \\
\hline Optimal & --- & 6 & 450 \\
locations and & & 3 & 150 \\
Size in kVAr & & 11 & 300 \\
& & 4 & 300 \\
\hline Total kVAr & --- & \multicolumn{2}{|c|}{1200} \\
\hline
\end{tabular}

From the results shown in Table I, it is observed that the bus number 13 had the lowest voltage of 0.944517 p.u before compensation and when compensation has been applied, this voltage has improved to 0.9694 p.u . It has also been seen that losses have been reduced by $50.71 \%$. 
Fig. 2 shows the voltage profile before compensation and the improved voltage profile after compensation on the various.

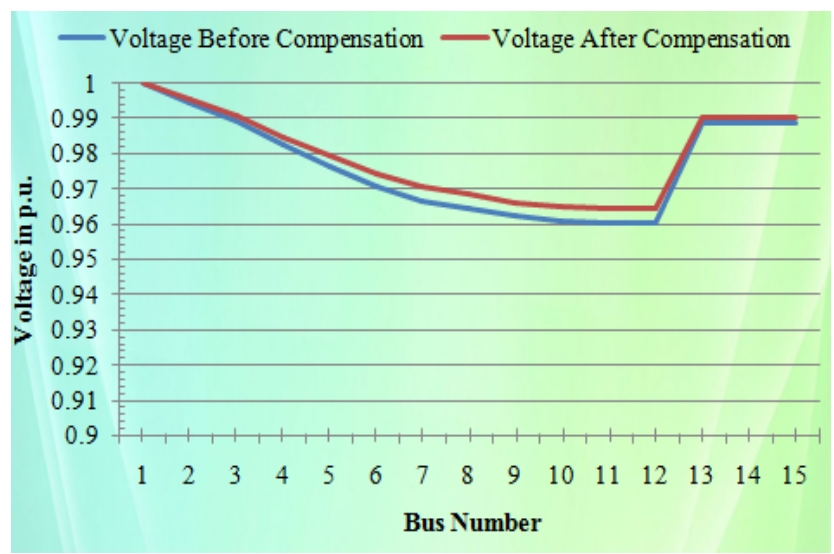

Fig. 2 Bus Voltages

\section{Conclusion}

The effectiveness of the proposed method for loss reduction by capacitor placement has been tested on 15-bus test radial distribution system. The rated line voltage of the system is $11 \mathrm{kV}$ and total reactive load is $1251 \mathrm{kVAr}$. Buses 6, 3, 11 and 4 are selected as the candidate buses for the capacitor placement using loss sensitivity analysis. On applying VDLF, the initial power loss was $61.8 \mathrm{~kW}$ and after capacitor placement using the proposed method it is reduced to $30.46 \mathrm{~kW}$. By placing the optimal capacity of capacitors at optimal locations, the voltages profile at all buses have been enhanced. It has also been observed that bus number 13 had the lowest voltage of 0.944517 p.u before compensation and when compensation has been applied, this voltage has improved to 0.9694 p.u.

\section{References}

[1] H. D. Chiang, J. C. Wang, O. Cockings, and H. D. Shin, "Optimal capacitor placements in distributions systems: Part 1 and 2," IEEE Trans. Power Del., Vol. 5, No. 2, pp. 634-649, Apr. 1990.

[2] Nerves, A.C.; Savet, F.J., "Voltage and Reactive-Power Control Optimization in a Distribution System," IEEE TENCON 2006 , 1417 Nov. 2006, pp. 1-4.

[3] M. E. Baran and F. F. Wu, "Optimal Capacitor Placement on Radial Distribution Systems”, IEEE Trans. on Power Delivery, Vol. 4, No. 1, January 1989.

[4] J. J. Grainger, and S. H. Lee, "Optimum Size and Location of Shunt Capacitors for Reduction of Losses on Distribution Feeders", IEEE Trans. on Power Apparatus and Systems, vol. 100, pp. 1105-1 118, March 1981.

[5] M. M. Hamada, M. A. A. Wahab, A. M. El-Sayed, H. A. Ramadan, “ A proposed strategy for capacitor allocation in radial distribution feeders," in Conf. 12th Middle East Power Systems Conf., MEPCON, Aswan, Egypt, 12-15 March 2008

[6] S.Jalilzadeh, S. Galvani, H. Hosseinian, F.Razavi, “Voltage Profile Modification Using Genetic Algorithm In Distribution Systems, " in Proceedings of the World Congress on Engineering and Computer Science 2007 WCECS 2007, October 24-26, 2007

[7] Mekhamer, S.F., Khattab, H.M., Mahmoud, A.M.A., "Solution of the Capacitor allocation problem in distribution feeders considering load variation: A modified simulated annealing based approach" in Proc. Int. Conf. power Systems Conference, 2006. (MEPCON 2006), 19-21 Dec. 2006, pp. 302-309.

[8] H Masoum, M.A.S., Jafarian, A., Ladjevardi, M., Fuchs, E.F., Grady, W.M., "Fuzzy approach for optimal placement and sizing of capacitor banks in the presence of harmonics ," IEEE Trans. Power on Delivery, vol. 19, no.2, pp 822-829, Apr. 2004.

[9] Etemadi, A.H., Fotuhi-Firuzabad,“ Distribution system reliability enhancement using optimal capacitor placement,” Generation, Transmission \& Distribution, IET, vol. 2, no. 5, pp. 621-631, July 2008.

[10] Tanuj Manglani, Y.S Shishodia, "Reduction in Power Losses on Distribution Lines using Bionic Random Search Plant growth Simulation Algorithm," International Journal of Recent Research and Review, vol. III, pp.8-14, September 2012.

[11] U. Ramesh Babu, V. Vijay Kumar Reddy and S. Tarakalyani, "Shunt Capacitor Position and Size Selection for Radial Distribution System using GA," International Journal of Engineering and Technology, Vol.2 , No.8, pp. 1345-1348, August 2012

[12] Prakash K., Sydulu, "A novel approach for optimal capacitor location and sizing of capacitors on radial distribution systems using loss sensitivity factors and alpha coefficients," IEEE Power Engineering Society General Meeting, 2006, pp. 1910-1913.

[13] D. Das, D.P. Kothari, A Kalam, Simple and Efficient Method for Load Flow Solution of Radial Distribution Networks, Electrical Power \& Energy Systems, Vol.17, no:5, pp.335-346, 1995. 